\title{
Absence of Symbiotic Leghemoglobins Alters Bacteroid and Plant Cell Differentiation During Development of Lotus japonicus Root Nodules
}

\author{
Thomas Ott, ${ }^{1}$ John Sullivan, ${ }^{2}$ Euan K. James, ${ }^{3}$ Emmanouil Flemetakis,${ }^{4}$ Catrin Günther, ${ }^{1}$ Yves Gibon, \\ Clive Ronson, ${ }^{2}$ and Michael Udvardi ${ }^{1}$ \\ ${ }^{1}$ Max-Planck-Institute of Molecular Plant Physiology, Am Mühlenberg 1, D-14471 Golm, Germany; ${ }^{2}$ Department \\ of Microbiology, University of Otago, Dunedin, New Zealand; ${ }^{3}$ College of Life Sciences, University of Dundee, Dundee, \\ DD1 5EH, United Kingdom; ${ }^{4}$ Agricultural University of Athens, Department of Agricultural Biotechnology, lera Odos, \\ Athens, Greece
}

Submitted 26 August 2008. Accepted 5 March 2009.

\begin{abstract}
During development of legume root nodules, rhizobia and their host plant cells undergo profound differentiation, which is underpinned by massive changes in gene expression in both symbiotic partners. Oxygen concentrations in infected and surrounding uninfected cells drop precipitously during nodule development. To assess what effects this has on plant and bacterial cell differentiation and gene expression, we used a leghemoglobin-RNA-interference (LbRNAi) line of Lotus japonicus, which is devoid of leghemoglobins and has elevated levels of free-oxygen in its nodules. Bacteroids in LbRNAi nodules showed altered ultrastructure indicating changes in bacterial differentiation. Transcript analysis of 189 plant and 192 bacterial genes uncovered many genes in both the plant and bacteria that were differentially regulated during nodulation of LbRNAi plants compared with the wild type (containing $L b$ and able to fix nitrogen). These included fix and nif genes of the bacteria, which are involved in microaerobic respiration and nitrogen fixation, respectively, and plant genes involved in primary and secondary metabolism. Metabolite analysis revealed decreased levels of many amino acids in nodules of LbRNAi plants, consistent with the defect in symbiotic nitrogen fixation of this line.
\end{abstract}

Symbiotic nitrogen fixation (SNF) by rhizobia in legumes is a major entry point for nitrogen into natural and agricultural systems (Graham and Vance 2003). SNF takes place in specialized plant organs called nodules, which develop on roots or stems following legume-Rhizobium signal exchanges that trigger plant meristem formation while allowing bacterial invasion of plant root hairs and underlying cortical cells (Brewin 2004). Invading bacteria are released from infection threads into cortical cells via endocytosis, which leaves them surrounded by a

Corresponding author: Michael Udvardi; E-mail: mudvardi@ noble.org

Present address of T. Ott: Ludwig-Maximilians-University, Institute of Genetics, Munich, Germany.

Present address of M. Udvardi: Plant Biology Division, Samuel Roberts Noble Foundation, Ardmore, OK, U.S.A.

Present address of C. Günther: HortResearch, Auckland, New Zealand.

* The $\boldsymbol{e}$-Xtra logo stands for "electronic extra" and indicates that two supplemental tables are published online. membrane of plant origin called the symbiosome membrane (SM) (Udvardi and Day 1997). Rhizobia continue to proliferate within the developing organelle, called a symbiosome, and this is matched by synthesis of SM and division of symbiosomes until infected plant cells are literally packed with thousands of symbiosomes, each containing one or a few bacteria. Development of legume nodules is accompanied by differentiation of both bacterial and plant cells, which is underpinned by global changes in gene expression in both organisms (Ampe et al. 2003; Becker et al. 2004; Capela et al. 2006; Colebatch et al. 2002, 2004; El Yahyaoui et al. 2004; Fedorova et al. 2002; Kouchi et al. 2004; Lohar et al. 2006; Pessi et al. 2007; Uchiumi et al. 2004) A key change in rhizobia during this differentiation is the induction of nitrogen fixation (nif) genes that encode the subunits of nitrogenase among other proteins.

Oxygen lability of nitrogenase, together with a limitation in alternative sources of nitrogen in many environments, provided the selective pressure for the evolution of a variety of strategies to protect the enzyme from oxygen in nitrogen-fixing organisms (Robson and Postgate 1980). In legume root nodules, restricted gaseous diffusion across the outer plant cell layers together with high rates of bacterial and mitochondrial respiration within the central tissues serve to reduce levels of intracellular free oxygen (Denison and Layzell 1991; Streeter and Salminen 1993; Webb and Sheehy 1991; Witty and Minchin 1994, 1998). The presence of millimolar concentrations of the oxygen-binding protein leghemoglobin within the cytoplasm of nodule cells serves to buffer free oxygen in the nanomolar range while ensuring rapid transport of oxygen to the sites of respiration (Appleby 1984, 1992; Bergersen and Turner 1993; Hunt and Layzell 1993). Removal of leghemoglobin from Lotus nodules via RNA interference (RNAi) resulted in an increase in nodule free oxygen, destabilization of nitrogenase, and a failure of SNF (Ott et al. 2005). Additionally, a decrease in hydrogen peroxide and alterations of the plant antioxidative machinery, probably due to the lack of leghemoglobin autooxidation, were observed (Günther et al. 2007).

Microaerobiosis is a prerequisite not only for nitrogenase activity but also for induction of nif, fix, and other genes in rhizobia (Ampe et al. 2003; Becker et al. 2004; Capela et al. 2006; Oke and Long 1999). Most of the genes induced during differentiation of Sinorhizobium meliloti into the nitrogenfixing bacteroid state are located on the "symbiotic" plasmids pSymA and pSymB, whereas the majority of repressed genes are chromosomal (Capela et al. 2006) The functions of many 
of the induced genes remain unknown. Among those repressed in bacteroids are genes involved in phosphate transport and utilization, iron uptake, and cell motility (Becker et al. 2004). Intriguingly, there is only partial overlap in the set of genes induced in rhizobia by low oxygen in vitro and those induced in bacteroids during nodule development (Barnett et al. 2004; Bobik et al. 2006; Pessi et al. 2007; Uchiumi et al. 2004). Comparison of in vitro and in planta data for bacterial gene expression is complicated by our relative ignorance of the physical and chemical conditions faced by rhizobia in nodules.

To study the effects of altered oxygen concentration on bacteroid differentiation and bacterial and plant gene expression, we made use of an Lb-RNAi line of Lotus japonicus with elevated levels of free oxygen within nodules compared with the wild type (Ott et al. 2005).

\section{RESULTS}

\section{Physiological and microscopic analysis of Lb-deficient plants.}

In earlier work, we reported on the major phenotypical features of Lotus Lb-RNAi plants, showing that general plant development under fully fertilized conditions is not altered and that nodules are colonized by rhizobia. Under N-limiting, symbiotic conditions, Lb-RNAi plants were smaller due to nitrogen starvation (Ott et al. 2005). To elucidate the dynamics of phenotype development in more detail, we performed an extensive time-course experiment. Wild-type and Lb-RNAi plants were inoculated with Mesorhizobium loti 1 week after germination and grown under symbiotic conditions for a further 5 weeks while growth parameters were recorded (Fig. 1). The two genotypes exhibited significant differences in shoot and root mass during the 5-week growth period (Fig. 1A and B). Whereas both wild-type and Lb-RNAi plants grew at a similarly slow rate during the first 3 weeks, wild-type plants grew more rapidly than Lb-RNAi plants from 3 weeks onward, presumably by virtue of SNF (Fig. 1A and B). In the course of
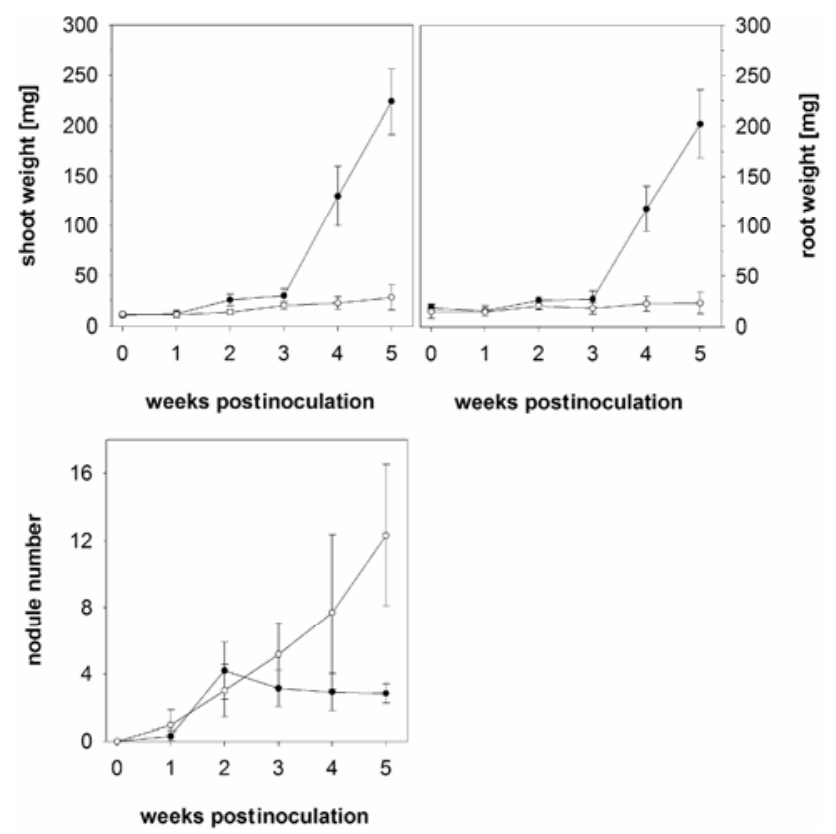

Fig. 1. Development of wild-type and leghemoglobin-RNA-interference (LbRNAi) plants and nodules. A, Shoot weight; B, root weight; and C, nodule number of wild-type (closed circles) and LbRNAi (open circles) plants over a 5-week period. Plants were grown for 2 weeks prior to inoculation with Mesorhizobium loti. Each data point represents mean and standard deviation of 10 plants. the experiment, Lb-RNAi plants developed symptoms of nitrogen starvation from week 4 onward, including leaf chlorosis and anthocyanin accumulation in shoot organs, as previously reported (data not shown).

Nodule development and number were similar in both genotypes for the first 2 weeks following inoculation. However, whereas wild-type nodules exhibited the pink color of leghemoglobin at approximately 10 days postinoculation (dpi) and continued to expand after $14 \mathrm{dpi}$, nodules of LbRNAi plants remained white and ceased to expand after $14 \mathrm{dpi}$. In addition to differences in nodule color and size beyond 14 dpi, LbRNAi nodules failed to develop the prominent lenticels of normal nodules (data not shown). On the other hand, the number of nodules produced by LbRNAi plants continued to increase linearly for 4 weeks after inoculation while the number on wild-type plants reached a plateau at a significantly lower level 1 to 2 weeks after inoculation (Fig. 1C).

To investigate alterations at the cellular level in more detail than previously reported (Ott et al. 2005), sections made from wild-type and LbRNAi nodules at 14 dpi were examined by light microscopy (Fig. 2). Accumulation of granular structures was found in the uninfected cells adjacent to the zone of infected cells of LbRNAi nodules (Fig. 2B and C). No such accumulation was observed in wild-type nodules (Fig. 2A). Lugol staining revealed these structures to be amyloplasts (Fig. 2D).

Previously, it was shown that the bacterial population inside LbRNAi nodules was reduced compared with the wild type (Ott et al. 2005). We used electron microscopy to determine whether differences existed in the disposition or morphology of bacteria in LbRNAi versus wild-type nodules (Fig. 3). At 14 dpi, symbiosomes were observed in both wild-type and LbRNAi nodules, indicating normal release of rhizobia from infection threads into plant cells (Fig. 3A and B). However, symbiosomes in LbRNAi nodules appeared to be larger and not as densely packed with bacteroids as in wild-type nodules (Fig. 3B) and, by $21 \mathrm{dpi}$, there was widespread breakdown of symbiosome membranes and the formation of numerous vacuoles or lytic vesicles, indicating the onset of senescence. Moreover, although bacteria at the periphery of infected cells of LbRNAi nodules looked like those of wild-type nodules, abnormally shaped (curved instead of rod-shaped) bacteria were found within the degrading symbiosomes in the center of such cells at $21 \mathrm{dpi}$ (Fig. 3D).

Transcriptional analysis of bacterial and plant genes.

To further investigate the effects of Lb deficiency on bacterial and plant cell differentiation during nodule development, we measured transcript levels of 189 plant and 192 bacterial genes in wild-type and LbRNAi nodules, using quantitative reversetranscription polymerase chain reaction (qRT-PCR). The aim was to establish a novel platform for high-throughput screening of gene expression during symbiotic interactions. Inclusion of a large and diverse set of genes in this platform allowed us to monitor expression of genes involved in many different processes in a more cost-effective manner than whole transcriptome analysis using expensive microarrays. Plant genes targeted in this analysis included many involved in primary metabolism, including sugar, organic acid, and amino acid metabolism, and genes involved in secondary metabolism (Supplementary Table IIc). Some of these and others included in the analysis were chosen because they were known to be induced during nodule development (Colebatch et al. 2002, 2004). The majority of the 192 bacterial genes targeted for expression analysis were chosen because they represent operons found within the $248-\mathrm{kb}$ conserved backbone sequence located within the symbiosis islands of both $M$. loti strains R7A and MAFF303099 (Kaneko et al. 2000; Sullivan et al. 2002). This DNA contains the nod, nif, 
and fix genes essential for SNF, and has been maintained in both strains since they diverged from a common ancestor. This region also contains a range of genes involved in metabolic and transport functions, including genes required for cofactor biosynthesis and phosphonate degradation, and one for carbon metabolism. Although the role of these genes is largely unknown, they may support bacteroid metabolism or bacterial survival in the rhizosphere environment. The genes mll7846, encoding the $30 \mathrm{~S}$ ribosomal protein $\mathrm{S} 6$; mlr1576, encoding a hypothetical protein; and $m l r 5562$, encoding a polynucleotide nucleotidyltransferase that represent putative housekeeping genes (Becker et al. 2004) were included to facilitate bacterial transcript normalization (Supplementary Table Ic). Primers for amplification of these sequences were designed from the $M$. loti strain MAFF303099 genome sequence. In our experiments, mlr5562 showed the most stable expression under all conditions; therefore, it was chosen for normalization of all other bacterial expression data.

Expression of none of the bacterial genes was detected by qRT-PCR of RNA from uninoculated root material, confirming the specificity of the primers targeting bacterial genes (data not shown). A total of 178 of the 192 bacterial primer pairs yielded a single product of the expected size following PCR of randomly primed reverse-transcribed nodule RNA, confirming their efficacy and gene specificity. Gene expression analysis was performed using RNA isolated from 14-, 21-, and 28-dayold nodules. Eight genes showed significantly different expression in LbRNAi nodules compared with those of the wild type at 14 dpi (cut-off $=$ twofold; $P<0.05$ ) (Fig. 4; Table 1). Three of these were expressed at lower levels in LbRNAi nodules than in those of the wild type, including nodP (mlr7575), which encodes a sulfate adenylate transferase required for the synthesis of $3^{\prime}$-phosphoadenine-5'-phosphosulfate (PAPS), a peptide ABC transporter (msi194) and a hypothetical protein (msi281). Five genes were more highly expressed in LbRNAi than in wild-type nodules at $14 \mathrm{dpi}$; namely, those encoding an oxygen-independent coproporphyrinogen III oxidase (hemN2), a cytochrome P450 mono-oxygenase (msi068), a Nod factor transporter component (nodJ), a nitrogen fixation protein (fixS), and a C4-dicarboxylate sensor $(d c t B)$.

Sixteen rhizobial genes were differentially expressed in wild-type and LbRNAi nodules at $21 \mathrm{dpi}$, including 3 up and 13 down in LbRNAi nodules compared with the wild type
(Table 1). By 28 dpi, when phenotypic differences were most evident (Fig. 1), the number of differentially expressed genes increased to 39, with 12 genes less highly and 27 genes more highly expressed in LbRNAi nodules than in the wild type. Among the genes expressed at lower levels in LbRNAi nodules compared with the wild type were several belonging to nif operons (nifH, nifK, and nifW) and other genes involved in metabolism ( $a s n B$, pepM, and $a d c$ ) (Table 1). In addition to $d c t B$ and $k b l$, which were more highly expressed at 14 and $21 \mathrm{dpi}$ in Lb-RNAi nodules, three genes belonging to the thiamine biosynthesis operon of $M$. loti were significantly induced in rhizobia hosted in LbRNAi nodules (Table 1).

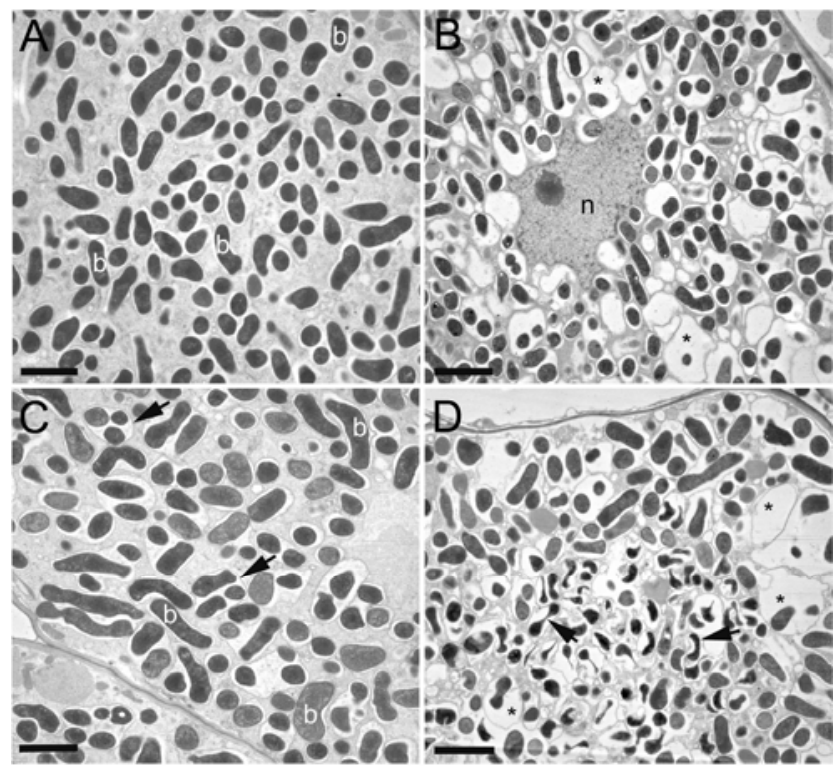

Fig. 3. Electron micrographs of wild-type and leghemoglobin-RNA-interference (LbRNAi) nodules. Nodules from plants at A and B, 14 days postinoculation (dpi) and $\mathbf{C}$ and $\mathbf{D}, 21 \mathrm{dpi}$ were embedded for transmission electron microscopy. Nodules from $\mathbf{A}$ and $\mathbf{C}$, wild-type plants contained normal symbiosomes with intact bacteroids (arrows). B, Some enlarged symbiosomes of LbRNAi nodules contained numerous bacteroids at 14 dpi, while others appeared to be devoid of bacteroids $(*)$. D, Central parts of LbRNAi nodules with many degraded symbiosomes $(*)$ containing misshapen bacteroids (arrows); $\mathrm{n}=$ nucleus. Bars represent $2 \mu \mathrm{m}$.
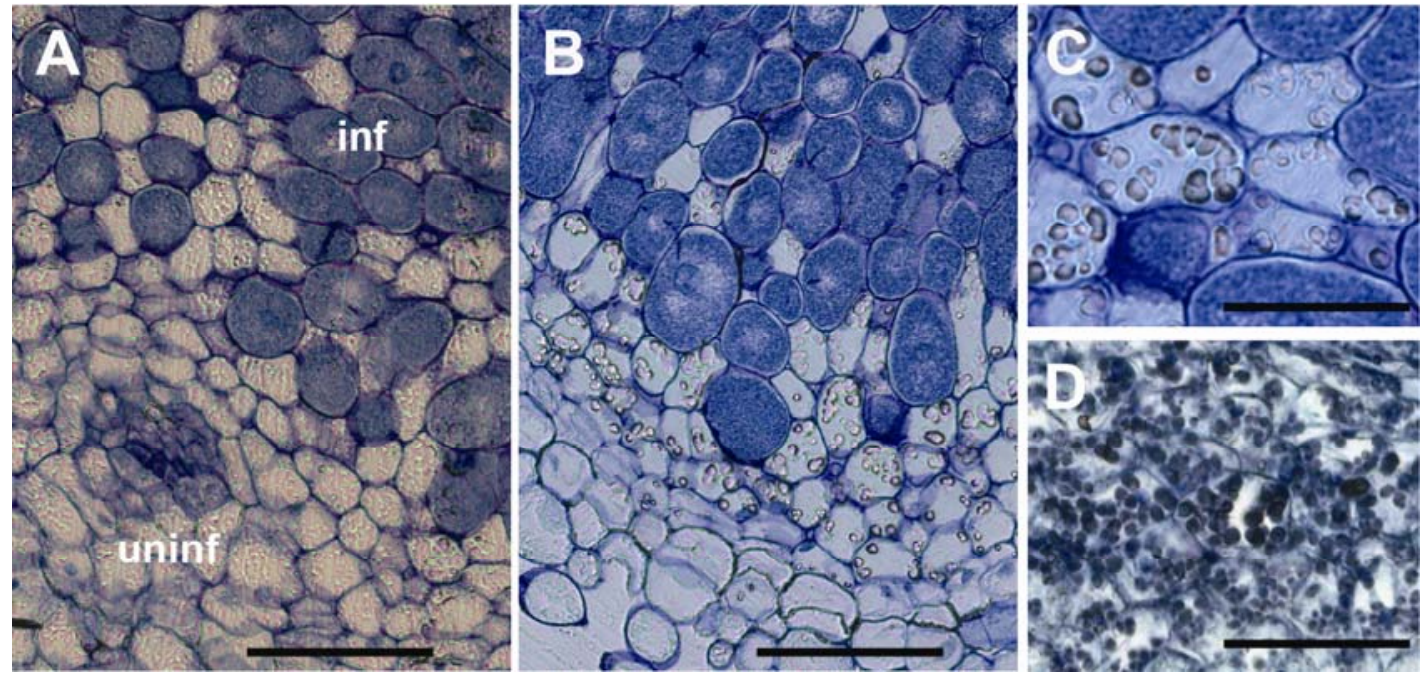

Fig. 2. Cellular morphology of nodules from wild-type and leghemoglobin-RNA-interference (LbRNAi) plants at 14 days postinoculation. Light micrographs of 5- $\mu \mathrm{m}$ nodule sections. Interzone between infected (inf) and uninfected (uninf) cells in nodules from A, wild-type and $\mathbf{B}$ through $\mathbf{D}$, LbRNAi plants. C, Amyloplasts revealed by D, Lugol staining was found in uninfected cells adjacent to infected cells. Bars indicate $50 \mu \mathrm{m}(\mathrm{A}$ and B) and $30 \mu \mathrm{m}$ $(\mathrm{C}$ and $\mathrm{D})$. 
Significant differences in the expression of plant genes at 21 dpi were also found between LbRNAi and wild-type nodules, including the following genes involved in primary carbon metabolism: $\beta$-amylase (TC14465), fructokinase (TC14218), transaldolase (TC14521), trehalose-6-phosphate synthase (TC9466), and 4-hydroxyphenylpyruvate dioxygenase (TC8682). These genes were two- to threefold more highly expressed in wild-type than LbRNAi nodules (Table 2). Major differences in expression of genes involved in amino acid metabolism were found in nodules of LbRNAi and wild-type plants. Most of these genes showed lower expression in LbRNAi nodules, including L-as-

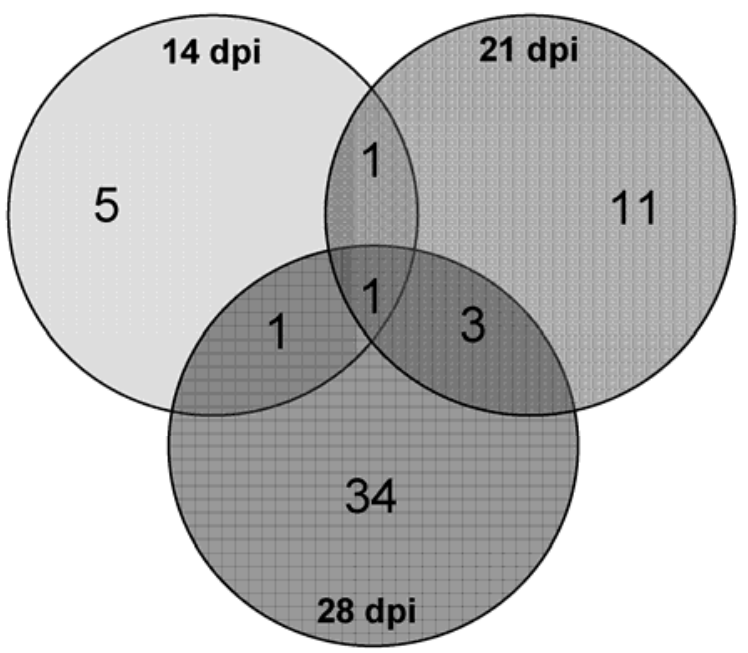

Fig. 4. Venn diagram of differentially regulated bacterial genes in leghemoglobin-RNA-interference (LbRNAi) versus wild-type nodules. Transcript levels of 178 bacterial genes in nodules 14, 21, and 28 days postinoculation were measured by quantitative reverse-transcription polymerase chain reaction. Genes were considered differentially regulated if the LbRNAi/wild-type transcript ratio was at least twofold different with a confidence interval of $P \leq 0.05$. paraginase (TC8339), threonine synthase (TC9527), and two amino acid acetyltransferases (TC18465/TC18260). Genes encoding a plastidic cysteine synthase 1 (TC17110), a copper amine oxidase (LjNEST6a8), and a putative diphenol oxidase gene (TC20034) were exclusively expressed in the wild type. Among the genes more highly expressed in LbRNAi nodules were the nodulin protein ENOD36A (TC8247), a proline dehydrogenase (TC7860) and a proline oxidase (TC7864), a thiazole biosynthetic enzyme precursor (TC14068), as well as two genes encoding calmodulin 7 (TC8059/TC8422) (Table 2). In total, expression of 81 of the 189 plant genes analyzed showed differential expression between the two genotypes when using a cut-off of twofold and a confidence interval of $P \leq 0.05$.

\section{Determination of amino acid levels in nodules.}

We found major alterations in expression of genes involved in amino acid metabolism; therefore, we performed high-pressure liquid chromatography (HPLC) to determine the concentrations of free amino acids in nodules of LbRNAi and wildtype plants harvested 6 weeks after inoculation with $M$. loti. Several amino acids were less abundant in LbRNAi nodules than in the wild type. Asparagine, one of the major export forms of nitrogen from Lotus nodules (Tajima et al. 2004) was fivefold less abundant in LbRNAi nodules than in the wild type (Table 3). LbRNAi nodules also contained less glutamate, histidine, alanine, arginine, gamma-amino-butyric-acid (GABA), tyrosine, and phenylalanine than wild-type nodules. In contrast, levels of aspartate and glutamine were not significantly changed. Significantly increased concentrations of tryptophan and valine were found in LbRNAi nodules compared with nodules from wild-type plants (Table 3).

\section{DISCUSSION}

Although plant development was not altered in LbRNAi plants under fully fertilized conditions (Ott et al. 2005), growth of these plants was significantly different from the wild type

Table 1. Ratios of expression levels of 25 bacterial genes that were found to be twofold differentially expressed in at least one of the timepoints ${ }^{\mathrm{a}}$

\begin{tabular}{|c|c|c|c|c|c|c|c|c|c|}
\hline \multirow[b]{2}{*}{ Gene } & \multicolumn{3}{|c|}{14 dpi } & \multicolumn{3}{|c|}{21 dpi } & \multicolumn{3}{|c|}{28 dpi } \\
\hline & $\mathbf{L} / \mathbf{W}$ & Stdev & $t$ Test & $\mathbf{L} / \mathbf{W}$ & Stdev & $t$ Test & $\mathbf{L} / \mathbf{W}$ & Stdev & $t$ Test \\
\hline рерм & 0.51 & 0.21 & 0.20 & 0.38 & 0.06 & 0.04 & 0.16 & 0.19 & 0.06 \\
\hline $\operatorname{adc}$ & 0.63 & 0.33 & 0.16 & 0.36 & 0.12 & 0.01 & 0.26 & 0.12 & 0.00 \\
\hline nifW & 0.92 & 0.32 & 0.32 & 0.57 & 0.22 & 0.03 & 0.33 & 0.07 & 0.03 \\
\hline nifH & 1.07 & 0.30 & 0.38 & 0.53 & 0.15 & 0.15 & 0.36 & 0.11 & 0.00 \\
\hline groeL & 0.84 & 0.42 & 0.23 & 0.50 & 0.39 & 0.16 & 0.39 & 0.14 & 0.03 \\
\hline $\operatorname{asn} B$ & 0.52 & 0.27 & 0.17 & 0.45 & 0.08 & 0.02 & 0.39 & 0.16 & 0.06 \\
\hline msi351 & 1.09 & 0.54 & 0.30 & 0.50 & 0.01 & 0.04 & 0.43 & 0.18 & 0.02 \\
\hline nifK & 1.39 & 0.80 & 0.46 & 0.56 & 0.07 & 0.05 & 0.46 & 0.29 & 0.02 \\
\hline msi281 & 0.42 & 0.18 & 0.04 & 0.57 & 0.15 & 0.05 & 1.01 & 0.53 & 0.34 \\
\hline$m l r 7575$ & 0.50 & 0.05 & 0.00 & 0.64 & 0.14 & 0.04 & 1.04 & 0.22 & 0.49 \\
\hline hemN2 & 2.80 & 1.32 & 0.01 & 2.17 & 0.98 & 0.05 & 1.26 & 0.64 & 0.47 \\
\hline fixS & 2.45 & 1.27 & 0.04 & 1.13 & 0.50 & 0.41 & 1.67 & 0.54 & 0.18 \\
\hline msil94 & 0.45 & 0.11 & 0.02 & 0.91 & 0.45 & 0.31 & 1.81 & 0.08 & 0.00 \\
\hline thiG & 1.08 & 0.50 & 0.37 & 0.84 & 0.20 & 0.15 & 2.12 & 0.86 & 0.05 \\
\hline thiS & 6.09 & 7.35 & 0.32 & 0.91 & 0.40 & 0.38 & 2.58 & 1.18 & 0.01 \\
\hline thiO & 0.88 & 0.14 & 0.10 & 1.12 & 0.49 & 0.36 & 2.65 & 0.55 & 0.01 \\
\hline$d c t B$ & 2.64 & 1.18 & 0.04 & 2.61 & 1.27 & 0.01 & 3.23 & 1.10 & 0.01 \\
\hline msil02 & 1.89 & 0.40 & 0.01 & 1.04 & 0.36 & 0.37 & 3.58 & 1.21 & 0.00 \\
\hline$m s i 248$ & 1.12 & 0.26 & 0.45 & 1.62 & 0.65 & 0.09 & 3.79 & 0.73 & 0.02 \\
\hline nodJ & 2.39 & 0.38 & 0.03 & nd & nd & nd & 4.09 & 1.23 & 0.00 \\
\hline msi021 & 1.09 & 0.41 & 0.42 & 1.27 & 0.51 & 0.32 & 4.53 & 2.21 & 0.03 \\
\hline msi031 & 0.99 & 0.62 & 0.35 & 2.00 & 1.98 & 0.26 & 4.71 & 1.93 & 0.03 \\
\hline omp2b1 & 0.80 & 0.33 & 0.14 & 0.99 & 0.33 & 0.42 & 6.17 & 3.15 & 0.01 \\
\hline$k b l$ & 1.84 & 0.20 & 0.02 & 2.03 & 0.48 & 0.00 & 6.53 & 0.92 & 0.01 \\
\hline msil75 & 0.54 & 0.05 & 0.02 & 0.86 & 0.43 & 0.39 & 6.84 & 3.62 & 0.03 \\
\hline msi068 & 2.32 & 0.25 & 0.04 & 0.49 & 0.44 & 0.36 & nd & nd & nd \\
\hline
\end{tabular}

\footnotetext{
${ }^{a}$ Student $t$-test-derived confidence interval of $P \leq 0.05$ was chosen. Values are shown as ratios of relative expression levels of leghemoglobin-RNA-inter-
} ference/wild type $(\mathrm{L} / \mathrm{W}) ; \mathrm{Stdev}=$ standard deviation; nd = not determined. Data were sorted according to expression levels at 28 days postinoculation (dpi). 
under symbiotic conditions (Fig. 1). LbRNAi plants developed more nodules than wild-type plants, presumably as a result of repetitive, unsuccessful attempts to perform SNF (Fig. 1). Similar nodulation phenotypes were observed for the Lotus sen 1 and sst 1 mutants, which are defective in SNF (Krusell et al. 2005; Suganuma et al. 2003). Although nodule development and bacterial infection appeared to proceed normally during the first 3 weeks after inoculation (Ott et al. 2005), microscopic analysis revealed several aberrations in LbRNAi nodules by $14 \mathrm{dpi}$ (Fig. 2). One of these was the accumulation of starch granules in uninfected cells (Fig. 2). Starch accumulation has also been reported for the Lotus senl mutant (Suganuma et al. 2003). Electron microscopy revealed morphological differences in rhizobia from the two genotypes, indicating defects in both bacteroid differentiation and the maintenance of symbiosome integrity. Indeed, the appearance of LbRNAi nodules with their enlarged symbiosomes, distorted bacteroids, and the presence of lytic vesicles suggested premature senescence, as has been observed in naturally senescent $L$. corniculatus nodules (Vance et al. 1982), L. japonicus nodules inoculated with symbiotically defective mutant strains of rhizobia (Szczyglowski et al. 1998), and the sen1 mutant (Suganuma et al. 2003). In addition to the signs of premature senescence, a lower number of bacteroids in the LbRNAi nodules is also indicative of reduced symbiotic effectiveness (Wood et al. 1985).

Rhizobia within nodules of LbRNAi lines exhibited a lower level of nifH gene expression compared with those in wildtype nodules and no NifH protein (Ott et al. 2005). Here, we showed that the lack of leghemoglobin had a broad impact on bacterial and plant gene expression in LbRNAi nodules (Tables 1 and 2; Fig. 4). Bacteroid differentiation during nodule development is normally accompanied by induction of a suite of nif and fix genes that are required for nitrogen fixation, efficient respiration under microaerobic conditions, and other symbiotic functions. Induction of nif and fix genes, including nifW, fixX, nifH, nifAl, fixU, nifK, nifD, fixI, fixJ, and presumably functionally related genes in the same operons, was attenuated in LbRNAi nodules, consistent with these genes being induced in response to microaerobiosis in developing wild-type nodules.

The nifA gene product induces expression of nif operons under low oxygen (Buikema et al. 1985; Sciotti et al. 2003; Thony et al. 1987). M. loti contains two copies of the nifA gene, designated nifA1 and nifA2 (Sullivan et al. 2002). The two genes are not functionally redundant because nifA2 mutants form Fix ${ }^{-}$nodules (Nukui et al. 2006; Sullivan et al. 2001). However, it is likely that nifAl is expressed during symbiosis in an NifA2-dependant manner because nifA1 is located immediately downstream from the NifA-regulated fix $A B C X$ operon. This operon, encoding a nitrogenase-specific electron transport system, was expressed at significantly lower levels in LbRNAi than in wild-type nodules. In Bradyrhizobium japonicum, fix $A B C$ transcription was shown to be regulated by low oxygen partial pressure (Gubler and Hennecke 1988). Consistent with this, nifA 1 was more highly expressed in 28-dpi wild-type nodules than in LbRNAi nodules.

Table 2. Transcript levels of 38 plant genes in nodules 21 days postinoculation that were found to be more than twofold differently expressed ${ }^{\text {a }}$

\begin{tabular}{|c|c|c|c|c|}
\hline Gene & TC & Average L/W & Stdev L/W & $t$ Test \\
\hline Putative diphenol oxidase & TC20034 & wt spec & nd & nd \\
\hline Copper amine oxidase & LjNEST6a8r & wt spec & nd & nd \\
\hline Plastidic cysteine synthase 1 & TC17110 & wt spec & nd & nd \\
\hline Anthranilate synthase & TC10990 & $5.096 \mathrm{E}-05$ & $1.287 \mathrm{E}-06$ & 0.004 \\
\hline Amino acid acetyltransferase & TC18260 & $2.117 \mathrm{E}-04$ & 4.096E-05 & 0.021 \\
\hline Tryptophan synthase & TC20070 & $2.127 \mathrm{E}-04$ & $2.759 \mathrm{E}-05$ & 0.013 \\
\hline Amino acid acetyltransferase & TC18465 & $4.452 \mathrm{E}-04$ & $8.816 \mathrm{E}-05$ & 0.008 \\
\hline Dihydrodipicolinate synthase & TC18091 & 0.001 & 2.027E-04 & 0.000 \\
\hline NADH glutamate dehydrogenase & TC10856 & 0.001 & 3.479E-04 & 0.027 \\
\hline Cystathionine-gamma-synthase & TC19008 & 0.001 & $3.030 \mathrm{E}-04$ & 0.012 \\
\hline Pyrroline-5-carboxylate reductase & TC15604 & 0.001 & $1.904 \mathrm{E}-04$ & 0.000 \\
\hline NAD-dependent mannitol dehydrogenase & TC10721 & 0.003 & 0.002 & 0.016 \\
\hline Cytochrome P450 & TC15466 & 0.004 & 0.001 & 0.013 \\
\hline Chalcone isomerase & NP591666 & 0.005 & 0.002 & 0.019 \\
\hline Threonine dehydratase/deaminase & TC18952 & 0.005 & 0.003 & 0.010 \\
\hline Threonine synthase & TC9527 & 0.007 & 0.001 & 0.007 \\
\hline Laccase & TC17617 & 0.008 & 0.001 & 0.003 \\
\hline L-asparaginase & TC8339 & 0.013 & 0.002 & 0.006 \\
\hline Putative diphenol oxidase & GENf079a06 & 0.018 & 0.002 & 0.003 \\
\hline Cytochrome P450 & TC8343 & 0.027 & 0.011 & 0.016 \\
\hline Fructokinase & TC14218 & 0.326 & 0.083 & 0.039 \\
\hline Trehalose-6-phosphate synthase & TC9466 & 0.381 & 0.111 & 0.019 \\
\hline$\beta$-Amylase & TC14465 & 0.432 & 0.076 & 0.012 \\
\hline 4-Hydroxyphenylpyruvate dioxygenase & TC8682 & 0.463 & 0.148 & 0.034 \\
\hline Transaldolase & TC14521 & 0.479 & 0.054 & 0.010 \\
\hline Glutamine synthetase, cytosolic isozyme & TC8035 & 4.424 & 0.876 & 0.028 \\
\hline Calmodulin 7 & TC8059 & 8.012 & 0.621 & 0.005 \\
\hline Asparagine synthase & TC14104 & 9.773 & 2.693 & 0.048 \\
\hline Thiazole biosynthetic enzyme precursor & TC14068 & 10.344 & 1.284 & 0.044 \\
\hline Proline oxidase & TC7864 & 10.718 & 10.818 & 0.047 \\
\hline Unknown protein & TC14085 & 11.929 & 5.097 & 0.007 \\
\hline Calmodulin 7 & TC8422 & 13.802 & 3.409 & 0.005 \\
\hline Proline dehydrogenase & TC7860 & 38.190 & 5.801 & 0.021 \\
\hline Unknown & TC14299 & 63.861 & 25.141 & 0.013 \\
\hline ENOD36A & TC8247 & 125.033 & 79.959 & 0.006 \\
\hline Putative auxin-induced protein & TC7966 & LbRNAi spec & nd & nd \\
\hline Uricase & TC14572 & LbRNAi spec & nd & nd \\
\hline Branched-chain amino acid aminotransferase & TC16062 & LbRNAi spec & nd & nd \\
\hline
\end{tabular}

${ }^{a}$ Student $t$-test-derived confidence interval of $P \leq 0.05$ was chosen. Values are shown as ratios of relative expression levels of leghemoglobin-RNA-interference $(\mathrm{LbRNAi}) /$ wild type $(\mathrm{wt})(\mathrm{L} / \mathrm{W}) ; \mathrm{TC}=$ tentative consensus sequence; Stdev = standard deviation; spec $=$ specific; nd $=$ not determined. 
The fixNOPQ operon encodes the high-affinity cytochromec oxidase cbb3, which is induced by microaerobiosis in vitro and is essential for SNF, presumably because it enables efficient respiration under oxygen-limiting conditions (Preisig et al. 1993, 1996). Increasing the redox potential of $S$. meliloti cells, assayed by screening mutants for higher capability to reduce 2,3,5-triphenyltetrazolium bromide (TTB), was correlated with increased expression of a cbb3-type oxidase and higher symbiotic effectiveness and $\mathrm{O}_{2}$ consumption rates (Yurgel et al. 1998). Interestingly, no significant differences (cut-off twofold) in expression of the fixNOPQ operon between LbRNAi and wild-type nodules were found at any timepoint despite altered oxygen concentrations in LbRNAi nodules. Consistent with this, no significant differences in transcript levels of the fixK gene, which encodes a regulator of the fix$N O P Q$ operon (Nellen-Anthamatten et al. 1998), were found. Apparently, oxygen levels in LbRNAi nodules reach a level low enough to induce fixNOPQ encoding the alternative oxidase but not sufficiently low to induce maximally the nif genes required for nitrogen fixation. These results suggest that the regulatory pathways controlling these two sets of genes are, at least in part, distinct. This is the case in B. japonicum, where the oxygen-sensitive FixLJ-FixK $K_{2}$ regulatory system is not directly linked to regulation of nifA expression. Experiments performed on liquid cultures demonstrated that expression of the FixLJ-controlled fixGHIS and fixNOPQ genes occurred at an oxygen concentration of 5\% whereas strong expression of the NifA-regulated gene nifH required oxygen concentrations $<2 \%$ (Nellen-Anthamatten et al. 1998; Preisig et al. 1993; Sciotti et al. 2003). The B. japonicum NifA protein contains several cysteine residues that have been implicated in the oxygen sensitivity of the protein. (Fischer et al. 1988; Morett et al. 1991). These residues are conserved in both the $M$. loti NifA1 and NifA2 proteins (Sullivan et al. 2001).

Surprisingly, a number of bacterial genes required for nodule development were more highly expressed in LbRNAi nodules than in those of the wild type. These included nodJ, nodD1, $\operatorname{nol} O$, nodM, nodA, nodI, and presumably other genes of the same regulon. They are normally induced in the presence of plant-derived flavonoids during the preinfection stages (Gottfert et al. 1992; Kosslak et al. 1987) but are also expressed during early phases of infection (Capela et al. 2006). It is possible that the material from these nodules contained more invading bacteria than that from wild-type nodules. Microarray studies that compared the expression of $S$. meliloti genes under free-living and symbiotic conditions also revealed significant expression of nodulation genes in bacteroids isolated from Medicago sativa nodules at 18 to 22 dpi (Becker et al. 2004). Expression of nodL and noe A has also been reported in mature nodules (Barnett et al. 2004; Becker et al. 2004; Capela et al. 2006).

Several genes involved in thiamine biosynthesis, including thiO, thiS, thiG, and thiD were more highly expressed in LbRNAi nodules than in the wild type. Genes of the thiCOS$G E D$ operon are involved in thiamine biosynthesis to form thiamine monophosphate, which is then phosphorylated to thiamine pyrophosphate. These metabolites were shown to act as negative regulators of the symbiotic terminal oxidase cbb3, which is essential for bacteroid respiration in Rhizobium etli (MirandaRios et al. 1997). The reason for the observed increased expression of thiamine biosynthetic genes in LbRNAi nodules is unclear. Thiamine biosynthesis is not essential for the formation of nodules or nitrogen fixation in Mesorhizobium loti (J. Sullivan, unpublished data) and not all rhizobia are capable of de novo thiamine biosynthesis (Karunakaran et al. 2006).

Expression of hundreds of plant genes is induced during legume nodule development, including many involved in glycolysis, carbon fixation, and amino acid metabolism (Colebatch et al. 2002, 2004; El Yahyaoui et al. 2004; Kouchi et al. 2004; Starker et al. 2006). Most of the amino acid biosynthesis genes assayed in this study were expressed at significantly lower levels in LbRNAi nodules than in the wild type (Table 2). This was reflected in lower levels of most amino acids in LbRNAi nodules (Table 3). The fivefold reduced accumulation in asparagine, one of the main forms of nitrogen export, is presumably associated with the lack of bacterial nitrogen fixation in these nodules (Ott et al. 2005). Interestingly, the levels of both alanine and GABA were found to be 2.5- and threefold lower in the LbRNAi nodules, respectively. Alanine and GABA are the two major amino acids that accumulate as a response to hypoxic stress conditions in plants (de Sousa and Sodek 2003; Miyashita and Good 2008), and they are proposed to be part of a protective mechanism against oxygen deficiency. Lower lev-

Table 3. Amino acid concentrations $\left(\mu \mathrm{mol} \times \mathrm{gFW}^{-1}\right)$ in nodules harvested at 6 weeks postinoculation ${ }^{\mathrm{a}}$

\begin{tabular}{|c|c|c|c|c|c|}
\hline \multirow[b]{2}{*}{ Amino acid } & \multicolumn{2}{|c|}{ Wild type } & \multicolumn{2}{|c|}{ LbRNAi } & \multirow[b]{2}{*}{$t$ Test } \\
\hline & Average & Stdev & Average & Stdev & \\
\hline Asparagine & 295.11 & 18.05 & 60.01 & 15.08 & 0.0001 \\
\hline GABA & 36.65 & 8.99 & 12.41 & 4.57 & 0.0001 \\
\hline Alanine & 83.98 & 8.77 & 35.36 & 10.05 & 0.0001 \\
\hline Phenylalanine & 4.76 & 0.70 & 2.48 & 0.64 & 0.0001 \\
\hline Tyrosine & 37.35 & 6.09 & 21.65 & 3.2 & 0.0001 \\
\hline$\beta$-Alanine & 2.22 & 0.73 & 1.35 & 0.44 & 0.024 \\
\hline Histidine & 13.57 & 2.00 & 8.49 & 1.05 & 0.0001 \\
\hline Arginine & 3.28 & 0.45 & 2.42 & 0.41 & 0.006 \\
\hline Glutamic acid & 57.3 & 8.53 & 43.04 & 7.94 & 0.013 \\
\hline Homoserine & 0.95 & 0.31 & 0.77 & 0.35 & 0.397 \\
\hline Glutamine & 5.62 & 1.02 & 4.87 & 1.21 & 0.300 \\
\hline Aspartic acid & 6.69 & 1.12 & 5.84 & 0.95 & 0.192 \\
\hline Lysine & 3.59 & 0.61 & 3.42 & 0.72 & 0.690 \\
\hline L-Isoleucine & 2.58 & 0.41 & 2.48 & 0.71 & 0.784 \\
\hline Leucine & 6.26 & 1.07 & 6.45 & 1.68 & 0.832 \\
\hline Glycine & 6.07 & 0.72 & 6.45 & 1.83 & 0.689 \\
\hline Serine & 10.37 & 1.8 & 12.39 & 3.2 & 0.250 \\
\hline Threonine & 4.59 & 0.56 & 6.04 & 1.55 & 0.086 \\
\hline Methionine & 0.44 & 0.17 & 0.60 & 0.25 & 0.289 \\
\hline Valine & 2.77 & 0.35 & 3.99 & 0.92 & 0.021 \\
\hline Tryptophane & 0.58 & 0.19 & 1.63 & 0.57 & 0.003 \\
\hline
\end{tabular}

${ }^{\text {a }}$ Measurements were done on five to 10 independent biological samples of wild-type and leghemoglobin-RNA-interference (LbRNAi) nodules; Stdev = standard deviation. Variance was tested using a student $t$ test. All pairs with a $P$ value of $\leq 0.05$ were regarded as being significantly different (in bold). 
els of these amino acids could be a direct result of the elevated oxygen concentration in the LbRNAi nodules. Thus, changes in plant cell nitrogen metabolism during normal nodule development may be dependent not only upon bacteroid differentiation and nitrogen fixation but also microaerobiosis per se.

Lack of nitrogen fixation in rhizobia of LbRNAi nodules and the associated decline in demand for energy may explain the reduction in expression of plant genes involved in glycolysis and carbon fixation, which are normally required to produce dicarboxylic acids for bacteroid respiration (Bergersen and Turner 1967; Copeland et al. 1989, 1995; Kurz and Larue 1977; Stowers and Elkan 1983; Udvardi and Day 1997). The reduced sink for carbon or energy in the bacteria may also explain the build-up of starch in plant cells of LbRNAi nodules (Fig. 2). Similar observations of starch accumulation have been made for other SNF-deficient mutants, including crinkle (Tansengco et al. 2003) and albl and fenl (Imaizumi-Anraku et al. 1997) of L. japonicus; ineffective mutants of alfalfa (Vance and Johnson 1983), soybean (Forrest et al. 1991), and pea (Gordon et al. 1999; Novak et al. 1995); and legume nodules infected by mutant rhizobia that are unable to fix nitrogen (Green and Emerich 1997).

Several genes involved in secondary metabolism that were previously found to be strongly induced during nodule development (Colebatch et al. 2002, 2004; El Yahyaoui et al. 2004; Kouchi et al. 2004), such as an isoliquiritigenin 2'- $O$-methyltransferase (TC14525), were found to be expressed at lower levels in LbRNAi nodules than in the wild type (Table 2). Interestingly, expression of several genes encoding proteins catalyzing final steps of lignin synthesis leading to the production of sinapyl-, coniferyl- and p-coumuaryl-alcohol was substantially lower in LbRNAi nodules (Table 2). These results are in line with the lower accumulation levels of phenylalanine, the immediate precursor of phenolic and flavonoid compounds, in LbRNAi plants. It would be interesting to determine whether LbRNAi nodules have lower lignin content than wildtype nodules of the same age. Because lignification typically increases with plant organ age (Boerjan et al. 2003), the lower activity of lignin biosynthesis genes might reflect the lack of maturation and early senescence of LbRNAi nodules (Fig. 1).

In summary, the data presented here indicate that presence of leghemoglobin influences bacteroid and plant cell differentiation during nodule development. Changes in one or both oxygen concentration or supply associated with the lack of leghemoglobin are probably directly involved in regulating the expression of rhizobial nif, fix, and other genes, and indirectly involved in the regulation of many plant genes, such as those involved in glycolysis and carbon fixation, and amino acid biosynthesis, which may be more directly regulated by changes in bacterial energy demand and by the products of nitrogen fixation, respectively.

\section{MATERIALS AND METHODS}

\section{Plant and bacterial growth.}

Dried L. japonicus seed (genotype Gifu) of wild-type and line 3 of the LbRNAi plants (Ott et al. 2005) were placed in a reaction tube and two volumes of $95 \%$ sulfuric acid were added. After $10 \mathrm{~min}$ of incubation, seed were carefully washed six times with sterile water before being sterilized in a $2 \%$ sodium hypochloride solution for 10 to $20 \mathrm{~min}$. After thoroughly rinsing the seed with sterile water, they were placed on wet filter paper for at least 3 days at a day and night cycle 16 and 8 $\mathrm{h}$, respectively, and $22^{\circ} \mathrm{C}$ for germination before being transferred onto square petri dishes containing one-quarter strength B\&D medium (Broughton and Dilworth 1971) for sterile cultivation or into pots containing soil or quartz sand for growth in the greenhouse. All plants were grown in the absence of external an $\mathrm{N}$ supply. When grown on agar plates, the upper third was removed before the medium was covered with a sterile wet filter paper. Seedlings were placed onto the upper edge of the filter and then grown vertically, with the root area being covered with black plastic foil, in a phytotron (cycle of 16 and $8 \mathrm{~h}$, day and night, respectively, at $22^{\circ} \mathrm{C}$ ). Plants were grown for 1 week before being inoculated with $M$. loti (strain R7A). Bacteria were cultured for 2 days at $28^{\circ} \mathrm{C}$ in tryptone yeast medium and $2 \mathrm{ml}$ of the culture was pelleted and resuspended in liquid one-quarter-strength B\&D medium. Plants were inoculated with $800 \mu$ l of a 1:50 dilution of this bacterial suspension. Nodules of different ages were harvested 14, 21, and 28 dpi.

\section{RNA extraction, cDNA synthesis, and real-time RT-PCR.}

Nodules from three biological replicates were harvested, immediately frozen in liquid nitrogen, and stored in a freezer at $-20^{\circ} \mathrm{C}$. Frozen tissue was ground using a Mixer Mill MM300 (Retch) for $2 \mathrm{~min}$. RNA was extracted from 100 to $200 \mathrm{mg}$ of ground tissue using an RNeasy extraction kit (Qiagen). Eluted RNA $(1 \mu \mathrm{l})$ was run on a $1 \%$ agarose gel to check for degradation, and RNA quantity was determined spectrophotometrically at $260 \mathrm{~nm}$. Total RNA $(1 \mu \mathrm{g})$ was used for subsequent cDNA synthesis. Total RNA was mixed with $1 \mu$ of $10 \times$ DNase reaction buffer and $1 \mathrm{U}$ of DNaseI (Ambion) in a total volume of $10 \mu \mathrm{l}$ and then incubated for $30 \mathrm{~min}$ at room temperature. After inactivation of the enzyme with $1 \mu \mathrm{l}$ of $50 \mathrm{mM}$ EDTA, $1 \mu \mathrm{l}$ of RNA was run on a $1 \%$ agarose gel again to check for RNA degradation. In addition, real-time RT-PCR was performed on each sample to test for successful DNA removal using an ubiquitin10-specific primer pair: LjUbi1f, 5'-TTCACCTTGTGCT CCGTCTTC-3' and LjUbi1r, 5'-AACAACAGCACACACAG CCAATCC-3'.

After confirmation of DNA degradation, cDNA synthesis was performed using SuperScriptII reverse transcriptase and random hexamer primers (Invitrogen), following the protocol of the supplier (Invitrogen). All RT-PCR steps and calculations of relative transcript amounts were as described previously (Czechowski et al. 2004).

All pipetting steps involving 96- and 384-well microplates were achieved using an Evolution P3 pipetting robot (PerkinElmer) equipped with a P50 96-channel head. Primer pairs, stored in 96-well microplates, were diluted 100 times (final concentration: $0.5 \mu \mathrm{M}$ ) into round-bottom 96-well plates (Sarstedt). Master mixes of $2.5 \mu \mathrm{l}$ of SYBR-Green (Applied Biosystems) and $0.5 \mu \mathrm{l}$ of diluted cDNA were prepared in 8well PCR strips (ABGene) and then robotically distributed into 384-well assay plates (Applied Biosystems) before $2 \mu \mathrm{l}$ of diluted primer pairs $(0.5 \mu \mathrm{M}$ each) were added to a final reaction volume of $5 \mu \mathrm{l}$. qPCR runs were performed in a Sequence Detection System 7900HT (Applied Biosystems) without technical replicates.

Primers were designed using Primer Express software (Applied Biosystems) using the same design parameters as described before (Czechowski et al. 2004, 2005). Sequences of all primers are provided in the online supporting material.

\section{Tissue fixation and sectioning for light microscopy.}

Nodules were fixed in Technovit 7100 (Heraeus Kulzer) following the protocol provided by the manufacturer, followed by stepwise dehydration of the material in 50,70, 90, 95, and $100 \%$ ethanol. Embedded plant material was cut to a thickness of 5 to $15 \mu \mathrm{m}$ using a Leica RM2155 microtome. Dried sections were stained in $1 \%$ Toluidine Blue solution for $2 \mathrm{~min}$ and rinsed with water afterward. Starch granules were detected by staining the sections in Lugol solution (iodide at $13 \mathrm{~g} / \mathrm{liter}$ and potassium iodide at $20 \mathrm{~g} / \mathrm{liter}$ ) for $5 \mathrm{~min}$ before being washed 
with water. Sections were observed using an Olympus Systemmicroscope BX41TF.

\section{Transmission electron microscopy.}

Transmission electron microscopy (TEM) was performed as described previously on Lotus nodules (James and Sprent 1999). Nodules were fixed in $2.5 \%$ glutaraldehyde in $0.1 \mathrm{M}$ sodium cacodylate $(\mathrm{pH} 7.0)$ overnight at $48^{\circ} \mathrm{C}$. The fixed nodules and nodulated roots were postfixed in $1 \%$ osmium tetroxide, dehydrated in an ethanol series, and then embedded in Durcupan epoxy resin (Sigma-Aldrich) for TEM analysis. Ultrathin sections $(70 \mathrm{~nm})$ were taken from the resin-embedded samples (LR White and Durcupan) using a Reichert Ultracut E ultramicrotome before being collected on pioloform-coated copper grids and stained with uranyl acetate (10 min) and lead citrate $(5 \mathrm{~min})$. Sections were viewed with a JEOL 1200 EX transmission electron microscope.

\section{Determination of amino acids.}

Nodule tissue (20 mg fresh weight) was ground in liquid nitrogen and extracted with $250 \mu \mathrm{l}$ of $80 \%$ ethanol for $20 \mathrm{~min}$ at $80^{\circ} \mathrm{C}$. After centrifugation at $20,800 \times g$, the supernatant was removed and retained, and the pellet was extracted again with $250 \mu \mathrm{l}$ of $50 \%$ ethanol for $20 \mathrm{~min}$ at $80^{\circ} \mathrm{C}$ and subjected to a second round of centrifugation. Then, $150 \mu \mathrm{l}$ of $80 \%$ ethanol was added to the remaining pellet, the material was incubated for further $20 \mathrm{~min}$ at $80^{\circ} \mathrm{C}$, and the supernatant was then transferred into a fresh tube. The supernatants were combined and later used for HPLC analysis of the amino acids after 2 mM HEPES ( $\mathrm{pH} 7.5$ ) was added to the total sample.

For derivatization, $35 \mu \mathrm{l}$ of sample was added to $35 \mu \mathrm{l}$ of ophthalic acid di-aldehyde reagent. After $1.5 \mathrm{~min}$, the mixture was injected into the Bio Tek High-Pressure Liquid Chromatography system. All steps and parameters used were described previously (Geigenberger et al. 1996).

\section{ACKNOWLEDGMENTS}

We thank R. Feil and B. Usadel (Max-Planck-Institute of Molecular Plant Physiology, Golm, Germany) for HPLC measurements and help with adaptation of MAPMAN for Lotus japonicus, respectively. The project was partially funded by the Max-Planck-Society, Germany.

\section{LITERATURE CITED}

Ampe, F., Kiss, E., Sabourdy, F., and Batut, J. 2003. Transcriptome analysis of Sinorhizobium meliloti during symbiosis. Genome Biol. 4(2):R15.

Appleby, C. A. 1984. Leghemoglobin and Rhizobium respiration. Annu. Rev. Plant Physiol. Plant Mol. Biol. 35:443-478.

Appleby, C. A. 1992. The origin and functions of haemoglobin in plants. Sci. Progress 76:365-398.

Barnett, M. J., Toman, C. J., Fisher, R. F., and Long, S. R. 2004. A dualgenome symbiosis chip for coordinate study of signal exchange and development in a prokaryote-host interaction. Proc. Natl. Acad. Sci. U.S.A. 101(47):16636-16641.

Becker, A., Berges, H., Krol, E., Bruand, C., Ruberg, S., Capela, D., Lauber, E., Meilhoc, E., Ampe, F., de Bruijn, F. J., Fourment, J., Francez-Charlot, A., Kahn, D., Kuster, H., Liebe, C., Puhler, A., Weidner, S., and Batut, J. 2004. Global changes in gene expression in Sinorhizobium meliloti 1021 under microoxic and symbiotic conditions. Mol. Plant-Microbe Interact. 17(3):292-303.

Bergersen, F. J., and Turner, G. L. 1967. Nitrogen fixation by bacteroid fraction of breis of soybean root nodules. Biochim. Biophys. Acta 141(3):507.

Bergersen, F. J., and Turner, G. L. 1993. Effects of concentration of substrates supplied to N2-fixing soybean bacteroids in flow chamber experiments. Proc. R. Soc. Lond. B 251:95-102.

Bobik, C., Meilhoc, E., and Batut, J. 2006. FixJ: A major regulator of the oxygen limitation response and late symbiotic functions of Sinorhizobium meliloti. J. Bacteriol. 188(13):4890-4902.

Boerjan, W., Ralph, J., and Baucher, M. 2003. Lignin biosynthesis. Annu. Rev. Plant Biol. 54:519-546.
Brewin, N. J. 2004. Plant cell wall remodeling in the Rhizobium-legume symbiosis. Crit. Rev. Plant Sci. 23(4):293-316.

Broughton, W. J., and Dilworth, M. J. 1971. Control of leghaemoglobin synthesis in snake beans. Biochem. J. 125(4):1075-1080.

Buikema, W. J., Szeto, W. W., Lemley, P. V., Orme-Johnson, W. H., and Ausubel, F. M. 1985. Nitrogen fixation specific regulatory genes of Klebsiella pneumoniae and Rhizobium meliloti share homology with the general nitrogen regulatory gene $n t r C$ of $K$. pneumoniae. Nucleic Acids Res. 13(12):4539-4555.

Capela, D., Filipe, C., Bobik, C., Batut, J., and Bruand, C. 2006. Sinorhizobium meliloti differentiation during symbiosis with alfalfa: A transcriptomic dissection. Mol. Plant-Microbe Interact. 19(4):363-372.

Colebatch, G., Kloska, S., Trevaskis, B., Freund, S., Altmann, T., and Udvardi, M. K. 2002. Novel aspects of symbiotic nitrogen fixation uncovered by transcript profiling with cDNA arrays. Mol. Plant-Microbe Interact. 15(5):411-420.

Colebatch, G., Desbrosses, G., Ott, T., Krusell, L., Montanari, O., Kloska, S., Kopka, J., and Udvardi, M. K. 2004. Global changes in transcription orchestrate metabolic differentiation during symbiotic nitrogen fixation in Lotus japonicus. Plant J. 39(4):487-512.

Copeland, L., Vella, J., and Hong, Z. 1989. Enzymes of carbohydrate metabolism in soybean nodules. Phytochemistry 28:57-61.

Copeland, L., Lee, H. S., and Cowlishaw, N. 1995. Carbon metabolism in chickpea nodules. Soil Biol. Biochem. 27:318-385.

Czechowski, T., Bari, R. P., Stitt, M., Scheible, W. R., and Udvardi, M. K. 2004. Real-time RT-PCR profiling of over 1,400 Arabidopsis transcription factors: Unprecedented sensitivity reveals novel root- and shootspecific genes. Plant J. 38(2):366-379.

Czechowski, T., Stitt, M., Altmann, T., Udvardi, M. K., and Scheible, W. R. 2005. Genome-wide identification and testing of superior reference genes for transcript normalization in Arabidopsis. Plant Physiol. 139(1):5-17.

Denison, R. F., and Layzell, D. B. 1991. Measurement of legume nodule respiration and $\mathrm{O} 2$ permeability by noninvasive spectrophotometry of leghemoglobin. Plant Physiol. 96(1):137-143.

de Sousa, C. A. F. and Sodek, L. 2003. Alanine metabolism and alanine aminotransferase activity in soybean (Glycine max) during hypoxia of the root system and subsequent return to normoxia. J. Exp. Bot. 50(1):1-8.

El Yahyaoui, F., Kuster, H., Ben Amor, B., Hohnjec, N., Puhler, A., Becker, A., Gouzy, J., Vernie, T., Gough, C., Niebel, A., Godiard, L., and Gamas, P. 2004. Expression profiling in Medicago truncatula identifies more than 750 genes differentially expressed during nodulation, including many potential regulators of the symbiotic program. Plant Physiol. 136(2):3159-3176.

Fedorova, M., van de Mortel, J., Matsumoto, P. A., Cho, J., Town, C. D., VandenBosch, K. A., Gantt, J. S., and Vance, C. P. 2002. Genome-wide identification of nodule-specific transcripts in the model legume Medicago truncatula. Plant Physiol. 130(2):519-537.

Fischer, H. M., Bruderer, T., and Hennecke, H. 1988. Essential and nonessential domains in the Bradyrhizobium japonicum NifA protein: Identification of indispensable cysteine residues potentially involved in redox reactivity and/or metal binding. Nucleic Acid Res. 16:2207-2224.

Forrest, S. I., Verma, D. P. S., and Dhindsa, R. S. 1991. Starch content and activities of starch-metabolizing enzymes in effective and ineffective root nodules of soybean. Can. J. Bot. 69:697-701.

Geigenberger, P., Lerchl, J., Stitt, M., and Sonnewald, U. 1996. Phloemspecific expression of pyrophosphatase inhibits long distance transport of carbohydrates and amino acids in tobacco plants. Plant Cell Environ. 19(1):43-55.

Gordon, A. J., Minchin, F. R., James, C. L., and Komina, O. 1999. Sucrose synthase in legume nodules is essential for nitrogen fixation. Plant Physiol. 120(3):867-877

Gottfert, M., Holzhauser, D., Bani, D., and Hennecke, H. 1992. Structural and functional analysis of two different nodD genes in Bradyrhizobium japonicum USDA110. Mol. Plant-Microbe Interact. 5(3):257-265.

Graham, P. H., and Vance, C. P. 2003. Legumes: Importance and constraints to greater use. Plant Physiol. 131(3):872-877.

Green, L. S., and Emerich, D. W. 1997. he formation of nitrogen-fixing bacteroids is delayed but not abolished in soybean infected by an alphaketoglutarate dehydrogenase-deficient mutant of Bradyrhizobium japonicum. Plant Physiol. 114:1359-1368.

Gubler, M., and Hennecke, H. 1988. Regulation of the fixA gene and fixBC operon in Bradyrhizobium japonicum. J. Bacteriol. 170(3):1205-1214.

Günther, C., Schlereth, A., Udvardi, M., and Ott, T. 2007. Metabolism of reactive oxygen species is attenuated in leghemoglobin-deficient nodules of Lotus japonicus. Mol. Plant-Microbe Interact. 20(12):1596-1603.

Hunt, S., and Layzell, D. B. 1993. Gas-exchange of legume nodules and the regulation of nitrogenase activity. Annu. Rev. Plant Physiol. Plant Mol. Biol. 44:483-511.

Imaizumi-Anraku, H., Kawaguchi, M., Koiwa, H., Akao, S., and Syono, K. 1997. Two ineffective-nodulating mutants of Lotus japonicus: Dif- 
ferent phenotypes caused by the blockage of endocytotic bacterial release and nodule maturation. Plant Cell Physiol. 38:871-881.

James, E. K., and Sprent, J. I. 1999. Development of N2-fixing nodules on the wetland legume Lotus uliginosus exposed to conditions of flooding. New Phytol. 142(2):219-231.

Kaneko, T., Nakamura, Y., Sato, S., Asamizu, E., Kato, T., Sasamoto, S. Watanabe, A., Idesawa, K., Ishikawa, A., Kawashima, K., Kimura, T., Kishida, Y., Kiyokawa, C., Kohara, M., Matsumoto, M., Matsuno, A., Mochizuki, Y., Nakayama, S., Nakazaki, N., Shimpo, S., Sugimoto, M., Takeuchi, C., Yamada, M., and Tabata, S. 2000. Complete genome structure of the nitrogen-fixing symbiotic bacterium Mesorhizobium loti. DNA Res. 7:331-338.

Karunakaran, R., Ebert, K., Harvey, S., Leonard, M. E., Ramachandran, V., and Poole, P. S. 2006. Thiamine is synthesized by a salvage pathway in Rhizobium leguminosarum bv. viciae strain 3841. J. Bacteriol. 188(18):6661-6668.

Kosslak, R. M., Bookland, R., Barkei, J., Paaren, H. E., and Appelbaum, E. R. 1987. Induction of Bradyrhizobium japonicum common nod genes by isoflavones isolated from Glycine max. Proc. Natl. Acad. Sci. U.S.A. 84(21):7428-7432.

Kouchi, H., Shimomura, K., Hata, S., Hirota, A., Wu, G. J., Kumagai, H., Tajima, S., Suganuma, N., Suzuki, A., Aoki, T., Hayashi, M., Yokoyama, T., Ohyama, T., Asamizu, E., Kuwata, C., Shibata, D., and Tabata, S. 2004. Large-scale analysis of gene expression profiles during early stages of root nodule formation in a model legume, Lotus japonicus. DNA Res. 11(4):263-274.

Krusell, L., Krause, K., Ott, T., Desbrosses, G., Kramer, U., Sato, S., Nakamura, Y., Tabata, S., James, E. K., Sandal, N., Stougaard, J., Kawaguchi, M., Miyamoto, A., Suganuma, N., and Udvardi, M. K. 2005. The sulfate transporter SST1 is crucial for symbiotic nitrogen fixation in Lotus japonicus root nodules. Plant Cell 17(5):1625-1636.

Kurz, W. G. W., and Larue, T. A. 1977. Citric-acid cycle enzymes and nitrogenase in nodules of Pisum Sativum. Can. J. Microbiol. 23(9):1197-1200.

Lohar, D. P., Sharopova, N., Endre, G., Penuela, S., Samac, D., Town, C., Silverstein, K. A., and VandenBosch, K. A. 2006. Transcript analysis of early nodulation events in Medicago truncatula. Plant Physiol. 140(1):221-234

Miranda-Rios, J., Morera, C., Taboada, H., Davalos, A., Encarnacion, S., Mora, J., and Soberon, M. 1997. Expression of thiamin biosynthetic genes (thiCOGE) and production of symbiotic terminal oxidase cbb3 in Rhizobium etli. J. Bacteriol. 179(22):6887-6893.

Miyashita, Y., and Good, A. G. 2008. NAD(H)-dependent glutamate dehydrogenase is essential for the survival of Arabidopsis thaliana during dark-induced carbon starvation. J. Exp. Bot. 59(3):667-680.

Morett, E., Fischer, H. M., and Hennecke, H. 1991. Influence of oxygen on DNA binding, positive control, and stability of the Bradyrhizobium japonicum NifA regulatory protein. J. Bacteriol. 173:3478-3487.

Nellen-Anthamatten, D., Rossi, P., Preisig, O., Kullik, I., Babst, M., Fischer, H. M., and Hennecke, H. 1998. Bradyrhizobium japonicum FixK2, a crucial distributor in the FixLJ-dependent regulatory cascade for control of genes inducible by low oxygen levels. J. Bacteriol. 180(19):5251-5255

Novak, K., Pesina, K., Nebesarova, J., Skrdleta, V., Lisa, L., and Nasinec, V. 1995. Symbiotic tissue degradation pattern in the ineffective nodules of three nodulation mutants of pea (Pisum sativum L.). Ann. Bot. 76:303-313

Nukui, N., Minamisawa, K., Ayabe, S., and Aoki, T. 2006. Expression of the 1-aminocyclopropane-1-carboxylic acid deaminase gene requires symbiotic nitrogen-fixing regulator gene nifA2 in Mesorhizobium loti MAFF303099. Appl. Environ. Microbiol. 72(7):4964-4969.

Oke, V., and Long, S. R. 1999. Bacterial genes induced within the nodule during the Rhizobium-legume symbiosis. Mol. Microbiol. 32(4):837-849.

Ott, T., van Dongen, J. T., Gunther, C., Krusell, L., Desbrosses, G., Vigeolas, H., Bock, V., Czechowski, T., Geigenberger, P., and Udvardi, M. K. 2005. Symbiotic leghemoglobins are crucial for nitrogen fixation in legume root nodules but not for general plant growth and development. Curr. Biol. 15(6):531-535.

Pessi, G., Ahrens, C. H., Rehrauer, H., Lindemann, A., Hauser, F., Fischer, H. M., and Hennecke, H. 2007. Genome-wide transcript analysis of Bradyrhizobium japonicum bacteroids in soybean root nodules. Mol. Plant-Microbe Interact. 20(11):1353-1363.

Preisig, O., Anthamatten, D., and Hennecke, H. 1993. Genes for a microaerobically induced oxidase complex in Bradyrhizobium japonicum are essential for a nitrogen-fixing endosymbiosis. Proc. Natl. Acad. Sci. U.S.A. 90(8):3309-3313.

Preisig, O., Zufferey, R., ThonyMeyer, L., Appleby, C. A., and Hennecke, H. 1996. A high-affinity $\mathrm{cbb}(3)$-type cytochrome oxidase terminates the symbiosis-specific respiratory chain of Bradyrhizobium japonicum. J. Bacteriol. 178(6): 1532-1538.

Robson, R. L., and Postgate, J. R. 1980. Oxygen and hydrogen in biologi- cal nitrogen-fixation. Annu. Rev. Microbiol. 34:183-207.

Sciotti, M. A., Chanfon, A., Hennecke, H., and Fischer, H. M. 2003. Disparate oxygen responsiveness of two regulatory cascades that control expression of symbiotic genes in Bradyrhizobium japonicum. J. Bacteriol. 185(18):5639-5642.

Starker, C. G., Parra-Colmenares, A. L., Smith, L., Mitra, R. M., and Long, S. R. 2006. Nitrogen fixation mutants of Medicago truncatula fail to support plant and bacterial symbiotic gene expression. Plant Physiol. 140(2):671-680.

Stowers, M. D., and Elkan, G. H. 1983. The transport and metabolism of glucose in cowpea rhizobia. Can. J. Microbiol. 29(4):398-406.

Streeter, J. G., and Salminen, S. O. 1993. Alterations in apoplastic and total solute concentrations in soybean nodules resulting from treatments known to affect gas-diffusion. J. Exp. Bot. 44(261):821-828.

Suganuma, N., Nakamura, Y., Yamamoto, M., Ohta, T., Koiwa, H., Akao, S., and Kawaguchi, M. 2003. The Lotus japonicus Sen1 gene controls rhizobial differentiation into nitrogen-fixing bacteroids in nodules. Mol. Genet. Genomics 269(3):312-320.

Sullivan, J. T., Brown, S. D., Yocum, R. R., and Ronson, C. W. 2001. The bio operon on the acquired symbiosis island of Mesorhizobium $s p$. strain R7A includes a novel gene involved in pimeloyl-CoA synthesis. Microbiology 147(Pt. 5):1315-1322.

Sullivan, J. T., Trzebiatowski, J. R., Cruickshank, R. W., Gouzy, J., Brown, S. D., Elliot, R. M., Fleetwood, D. J., McCallum, N. G., Rossbach, U., Stuart, G. S., Weaver, J. E., Webby, R. J., De Bruijn, F. J., and Ronson, C. W. 2002. Comparative sequence analysis of the symbiosis island of Mesorhizobium loti strain R7A. J. Bacteriol. 184(11):3086-3095.

Szczyglowski, K., Shaw, R. S., Wopereis, J., Copeland, S., Hamburger, D., Kasiborski, B., Dazzo, F. B., and De Bruijn, F. J. 1998. Nodule organogenesis and symbiotic mutants of the model legume Lotus japonicus. Mol. Plant-Microbe Interact. 11(7):684-697.

Tajima, S., Nomura, M., and Kouchi, H. 2004. Ureide biosynthesis in legume Nodules. Front. Biosci. 9:1374-1381.

Tansengco, M. L., Hayashi, M., Kawaguchi, M., Imaizumi-Anraku, H., and Murooka, Y. 2003. crinkle, a novel symbiotic mutant that affects the infection thread growth and alters the root hair, trichome, and seed development in Lotus japonicus. Plant Physiol. 131(3):1054-1063.

Thony, B., Fischer, H. M., Anthamatten, D., Bruderer, T., and Hennecke, H. 1987. The symbiotic nitrogen fixation regulatory operon (fixRnifA) of Bradyrhizobium japonicum is expressed aerobically and is subject to a novel, nifA-independent type of activation. Nucleic Acids Res. 15(20):8479-8499.

Uchiumi, T., Ohwada, T., Itakura, M., Mitsui, H., Nukui, N., Dawadi, P., Kaneko, T., Tabata, S., Yokoyama, T., Tejima, K., Saeki, K., Omori, H., Hayashi, M., Maekawa, T., Sriprang, R., Murooka, Y., Tajima, S. Simomura, K., Nomura, M., Suzuki, A., Shimoda, Y., Sioya, K., Abe, M., and Minamisawa, K. 2004. Expression islands clustered on the symbiosis island of the Mesorhizobium loti genome. J. Bacteriol. 186(8):2439-2448

Udvardi, M. K., and Day, D. A. 1997. Metabolite transport across symbiotic membranes of legume nodules. Annu. Rev. Plant Physiol. Plant Mol. Biol. 48:493-523.

Vance, C. P., and Johnson, E. B. 1983. Plant determined ineffective nodules in alfalfa (Medicago sativa): Structural and biochemical comparison. Can. J. Bot. 61:49-61.

Vance, C. P., Johnson, L. E. B., Stade, S., and Groat, R. G. 1982. Birdsfoot trefoil (Lotus corniculatus) root nodules: Morphogenesis and the effect of forage harvest on structure and function. Can. J. Bot. 60:505-518.

Webb, J., and Sheehy, J. E. 1991. Legume nodule morphology with regard to oxygen diffusion and nitrogen-fixation. Ann. Bot. 67(1):77-83.

Witty, J. F., and Minchin, F. R. 1994. A new method to detect the presence of continuous gas-filled pathways for oxygen diffusion in legume nodules. J. Exp. Bot. 45:967-978.

Witty, J. F., and Minchin, F. R. 1998. Hydrogen measurements provide direct evidence for a variable physical barrier to gas diffusion in legume nodules. J. Exp. Bot. 49(323):1015-1020.

Wood, S. M., Layzell, D. B., Newcomb, W., and Pankhurst, C. E. 1985. A morphometric study of effective nodules induced by Rhizobium loti and Bradyrhizobium sp. (Lotus) on Lotus pedunculatus. Can. J. Bot. 63:4353.

Yurgel, S. N., Soberon, M., Sharypova, L. A., Miranda, J., Morera, C., and Simarov, B. V. 1998. Isolation of Sinorhizobium meliloti Tn5 mutants with altered cytochrome terminal oxidase expression and improved symbiotic performance. FEMS (Fed. Eur. Microbiol. Soc.) Microbiol. Lett. 165(1):167-173.

\section{AUTHOR-RECOMMENDED INTERNET RESOURCE}

RhizoBase database: bacteria.kazusa.or.jp/rhizobase 